\title{
An unusual electrocardiogram
}

\author{
Zhili Li $\cdot$ Fujun Shang $\cdot$ Wei Zhang $\cdot$ Yi Wang
}

Published online: 12 February 2011

(C) Springer Media / Bohn Stafleu van Loghum 2011

\begin{abstract}
A 30-year-old woman was admitted to our Cardiology Department with sustained palpitations for $10 \mathrm{~h}$. She had suffered from paroxysmal palpitations for 3 months. This happened two to five times every week, especially in the month before admission and syncope occurred occasionally. Intravenous injection of propafenone or adenosine was used to terminate the acute episodes of palpitations. There were two different types of onset electrocardiogram (ECG) with a fast and regular rhythm, one was with normal QRS complexes, the other was with wide QRS complexes. The
\end{abstract}

heart was normal on an ultrasonic examination and emission computed tomography. The usual electrocardiogram was undertaken (Fig. 1, upper panel). The significant episode was documented by Holter monitoring (Fig. 1, lower panel). What is your diagnosis?

\section{Answer}

You will find the answer elsewhere in this issue. 
Fig. 1 The usual 12-lead surface ECG (upper panel). Paper speed is as usual $(25 \mathrm{~mm} / \mathrm{s})$ and the voltage is half the usual $(5 \mathrm{mv} / \mathrm{mm})$. The significant episode documented by Holter monitoring (lower panel). Paper speed is as usual $(25 \mathrm{~mm} / \mathrm{s})$ and voltage is as usual $(10 \mathrm{mv} / \mathrm{mm})$

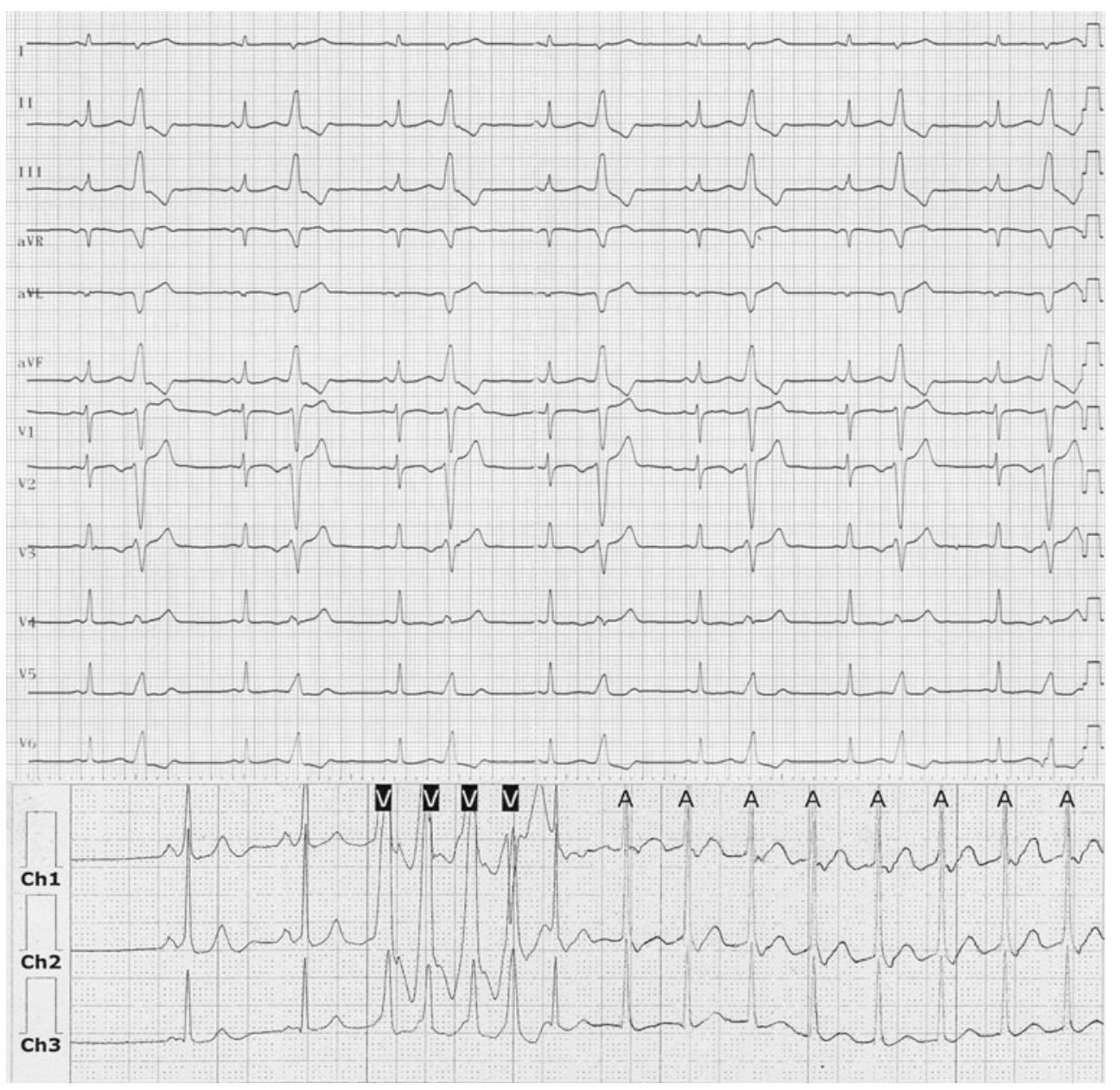

